\title{
Subcellular distribution of glutathione and cysteine in cyanobacteria
}

\author{
Bernd Zechmann • Ana Tomašić • Lucija Horvat • \\ Hrvoje Fulgosi
}

Received: 19 October 2009 / Accepted: 19 February 2010/Published online: 28 March 2010

(C) The Author(s) 2010. This article is published with open access at Springerlink.com

\begin{abstract}
Glutathione plays numerous important functions in eukaryotic and prokaryotic cells. Whereas it can be found in virtually all eukaryotic cells, its production in prokaryotes is restricted to cyanobacteria and proteobacteria and a few strains of gram-positive bacteria. In bacteria, it is involved in the protection against reactive oxygen species (ROS), osmotic shock, acidic conditions, toxic chemicals, and heavy metals. Glutathione synthesis in bacteria takes place in two steps out of cysteine, glutamate, and glycine. Cysteine is the limiting factor for glutathione biosynthesis which can be especially crucial for cyanobacteria, which rely on both the sufficient sulfur supply from the growth media and on the protection of glutathione against ROS that are produced during photosynthesis. In this study, we report a method that allows detection and visualization of the subcellular distribution of glutathione in Synechocystis sp. This method is based on immunogold cytochemistry with glutathione and cysteine antisera and computer-supported transmission electron microscopy. Labeling of glutathione and cysteine was restricted to the cytosol and interthylakoidal spaces. Glutathione and cysteine could not be detected in carboxysomes, cyanophycin granules, cell walls, intrathylakoidal spaces, periplasm, and vacuoles. The accuracy of the glutathione and cysteine labeling is
\end{abstract}

B. Zechmann $(\square)$

Institute of Plant Sciences, University of Graz,

Schubertstraße 51,

8010 Graz, Austria

e-mail: bernd.zechmann@uni-graz.at

A. Tomašić • L. Horvat • H. Fulgosi

Department of Molecular Biology, Ruđer Bošković Institute,

Bijenička 54,

10000 Zagreb, Croatia supported by two observations. First, preadsorption of the antiglutathione and anticysteine antisera with glutathione and cysteine, respectively, reduced the density of the gold particles to background levels. Second, labeling of glutathione and cysteine was strongly decreased by $98.5 \%$ and $100 \%$, respectively, in Synechocystis sp. cells grown on media without sulfur. This study indicates a strong similarity of the subcellular distribution of glutathione and cysteine in cyanobacteria and plastids of plants and provides a deeper insight into glutathione metabolism in bacteria.

Keywords Compartmentation · Electron microscopy · Glutathione $\cdot$ Immunogold labeling $\cdot$ Histochemistry $\cdot$ Synechocystis

\section{Introduction}

Glutathione ( $\gamma$-L-glutamyl-L-cysteinyl-glycine) is the most important nonprotein thiol in plants, animals, and eukaryotes with the exception of those that do not contain mitochondria and chloroplasts (Fahey and Sundquist 1991; Rennenberg 2001; Masip et al. 2006; Forman et al. 2009; Foyer and Noctor 2009; Lafiti et al. 2009). Its production in prokaryotes is restricted to cyanobacteria and proteobacteria and a few strains of gram-positive bacteria. Glutathione has not been detected so far in any other subgroups of eubacteria or in archaebacteria with the exception of green sulfur bacteria (Fahey et al. 1987; Fahey and Sundquist 1991; Newton et al. 1996; Masip et al. 2006). Nevertheless, some groups of bacteria that do not contain glutathione produce different low molecular thiols (cf. Fahey 2001) which fulfill similar functions as glutathione, thus demonstrating the importance of glutathione and low molecular 
thiols in bacteria. The roles of glutathione in metabolism of bacteria are similar to those in plants, animals, and eukaryotes. One of the most important functions of glutathione in bacteria is the protection against oxidative stress which occurs when cells are exposed to reactive oxygen species (ROS) such as $\mathrm{H}_{2} \mathrm{O}_{2}$, alky hydroperoxides, hydroxyl radicals, and superoxides (Storz and Imlay 1999; Carmel-Harel and Storz 2000; Masip et al. 2006; Foyer and Noctor 2009; Lafiti et al. 2009). This is especially critical in cyanobacteria which perform aerobic photosynthesis and can produce large amounts of ROS that could destroy membranes, proteins, RNA, and DNA, leading to mutations and eventually cell death (Fahey 2001; Tausz 2001; Masip et al. 2006; van Breusegem and Dat 2006; Foyer and Noctor 2009; Lafiti et al. 2009). Other functions of glutathione in bacteria are the protection against osmotic shock (Csonka 1989; McLaggan et al. 1990; Smirnova et al. 2001), acidic conditions (Ferguson and Booth 1998; Riccillo et al. 2000), toxic chemicals such as methylglyoxal, chlorine compounds $\left(\mathrm{HOCl}, \mathrm{NH}_{2} \mathrm{Cl}\right)$, and heavy metals (Chesney et al. 1996; Ferguson and Booth 1998; Masip et al. 2006). Additionally, glutathione is important as a reducing agent for ribonucleotides and other substrates and protects proteins from being irreversibly oxidized by ROS and reactive nitrogen species through a process called glutathionylation (c.f. Hurd et al. 2005; Masip et al. 2006). Glutathionylation (the formation of mixed disulfides between proteins, cysteine, and glutathione) is mainly important during situations of oxidative stress. When cells are removed from the oxidative environment, glutathionylated proteins can be reduced to their native state, e.g., by glutaredoxins.

Glutathione synthesis in bacteria occurs in two ATPdepending steps. In the first step, cysteine and glutamate are linked together by $\gamma$-glutamyl-cysteine synthetase, and in the second step glycine is added to $\gamma$-glutamyl-cysteine to form the final product glutathione. This step is triggered by glutathione synthetase (c.f. Copley and Dhillon 2002; Masip et al. 2006). Glutathione synthesis is feedbackinhibited by the formation of $\gamma$-glutamyl-cysteine (glutathione itself can inhibit the activity of $\gamma$-glutamyl-cysteine synthetase) or by the availability of its amino acids. The concentration of cysteine seems to be the main limiting amino acid for glutathione synthesis which is especially essential in cyanobacteria that rely on sufficient sulfur supply from the growth medium and on the protection of glutathione, especially during oxidative stress situations (c.f. Copley and Dhillon 2002; Masip et al. 2006). Cysteine is the most important sulfur source for biosynthesis of most other thiols and essential for cell metabolism in bacteria (Fahey 2001).

Even though the roles of glutathione (and cysteine), its synthesis, and degradation are well understood, its subcel- lular distribution within cyanobacteria still remains unclear. Nevertheless, information about the subcellular distribution of glutathione and cysteine is essential in order to gain a deeper insight into glutathione metabolism and into the subcellular importance of glutathione in bacteria. Therefore, the present study was aimed to develop a method that allows the visualization and quantification of the subcellular distribution of glutathione and cysteine in cyanobacteria. For this purpose, an immunohistochemical method was adapted to Synechocystis sp. which has been previously developed to detect the subcellular distribution of glutathione and cysteine in plant and animal tissue (Hjelle et al. 1994; Huster et al. 1998; Zechmann et al. 2006a, 2008). To verify the accuracy and specificity of this method, changes in glutathione and cysteine contents were quantified in cells grown on media with and without sulfur.

\section{Materials and methods}

Bacterial strains and culture conditions

Cyanobacteria (Synechocystis sp. PCC6803) were cultivated in BG11 medium at $30^{\circ} \mathrm{C}$ under constant light conditions $\left(20 \mu \mathrm{mol} \mathrm{m} \mathrm{m}^{-2} \mathrm{~s}^{-1}\right)$ for 7 days. One part of the culture was transferred into BG11 medium without sulfur. Fixation and embedding were performed with Synechocystis sp. grown on medium with sulfur for 7 days and without sulfur for $48 \mathrm{~h}$ as a stagnation of bacteria growth could be observed after that time (Fig. 1). Cell growth was monitored by spectrophotometric measurements of optical density at $730 \mathrm{~nm}$. Before fixation cyanobacteria were centrifuged $(2,500 \times g$ was used during centrifugation between each step throughout sample preparation) for $3 \mathrm{~min}$, and the pellet was resuspended in $0.06 \mathrm{M}$ Sørensen phosphate buffer (pH 7.2; Sørensen 1909). After another centrifugation step,

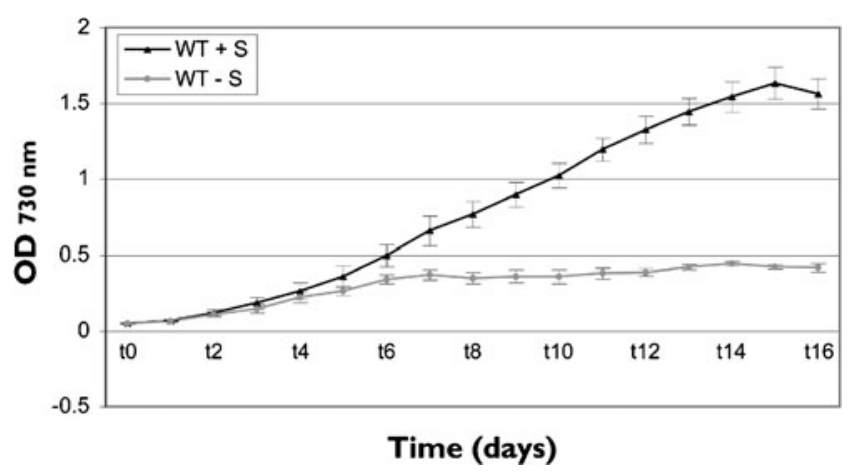

Fig. 1 Photoautotrophical growth curves of Synechocystis sp. PCC6803 wild-type cultivated in conditions with (WT + S) and without sulfur (WT $-\mathrm{S}$ ) added to the BG-11 medium. Error bars indicate standard error of the mean 
samples were resuspended and fixed for 90 min either in (a) $2.5 \%$ glutardialdehyde $/ 2.5 \%$ paraformaldehyde in $0.06 \mathrm{M}$ Sørensen phosphate buffer (pH 7.2; Sørensen 1909) for ultrastructural investigations or (b) in $2.5 \%$ paraformaldehyde $/ 0.5 \%$ glutardialdehyde in $0.06 \mathrm{M}$ Sørensen phosphate buffer ( $\mathrm{pH}$ 7.2) for cytohistochemical analysis.

For ultrastructural analysis, samples were then rinsed in buffer (four times, $15 \mathrm{~min}$ each) and postfixed in $2 \%$ potassium permanganate in $0.06 \mathrm{M}$ Sørensen phosphate buffer for $90 \mathrm{~min}$ at room temperature (RT). The samples were then dehydrated in increasing concentrations of acetone $(50 \%, 70 \%, 90 \%$, and $100 \%)$. Pure acetone was then exchanged by propylene oxide, and specimen were gradually infiltrated with increasing concentrations of Agar 100 epoxy resin $(30 \%, 60 \%$, and $100 \%)$ mixed with propylene oxide for a minimum of $3 \mathrm{~h}$ per step. Samples were finally embedded in pure, fresh Agar 100 epoxy resin (Agar Scientific Ltd., Stansted, UK) and polymerized at $60^{\circ} \mathrm{C}$ for $48 \mathrm{~h}$.

For cytohistochemical investigations, samples were rinsed in buffer (four times, $15 \mathrm{~min}$ each) after fixation and then dehydrated in increasing concentrations of acetone $(50 \%, 70 \%$, and $90 \%)$ for two times for $10 \mathrm{~min}$ each. Subsequently, specimens were gradually infiltrated with increasing concentrations of LR-White resin $(30 \%, 60 \%$, and 100\%; London Resin Company Ltd., Berkshire, UK) mixed with acetone (90\%) for a minimum of $3 \mathrm{~h}$ per step. Samples were finally embedded in pure, fresh LR-White resin and polymerized at $50^{\circ} \mathrm{C}$ for $48 \mathrm{~h}$ in small plastic containers under anaerobic conditions. Ultrathin sections $(80 \mathrm{~nm})$ were cut with a Reichert Ultracut S ultramicrotome. For ultrastructural investigations, sections were poststained for $5 \mathrm{~min}$ with lead citrate and for $15 \mathrm{~min}$ with uranyl acetate at RT before they were observed with a Philips CM10 transmission electron microscope. For cytohistochemical investigations, sections remained either unstained or were stained for $15 \mathrm{~s}$ with $2 \%$ uranyl acetate dissolved in aqua bidest at RT.

\section{Cytohistochemical investigations}

Immunogold labeling of glutathione and cysteine was done with ultrathin sections on nickel grids as described in Zechmann et al. (2006b, 2008) for plant tissue. Briefly, samples were blocked with $2 \%$ bovine serum albumin (BSA) in phosphate-buffered saline (PBS, $\mathrm{pH}$ 7.2) for $20 \mathrm{~min}$ at RT. The samples were then treated with the primary antibodies (antiglutathione rabbit polyclonal $\mathrm{IgG}$ and anticysteine rabbit polyclonal $\mathrm{IgG}$, Millipore Corp., Billerica, MA, USA) diluted 1:50 (glutathione antibody) and 1:300 (cysteine antibody) in PBS containing 1\% goat serum for $2 \mathrm{~h}$ at RT. After a short rinse in PBS (three times, $5 \mathrm{~min}$ ), the samples were incubated with a $10-\mathrm{nm}$ gold-conjugated secondary antibody (goat antirabbit IgG, British BioCell International, Cardiff, Great Britain) diluted 1:50 in PBS for $90 \mathrm{~min}$ at RT. After a short wash in PBS (three times, $5 \mathrm{~min}$ ) and distilled water (two times, $5 \mathrm{~min}$ ), labeled grids were either immediately observed in a Philips CM10 transmission electron microscope or poststained with uranyl acetate (15 s). Poststaining with uranyl acetate was applied to facilitate the distinction of different cell structures, enabling a clearer identification of the investigated organelles.

The selectivity and proper affinity of the primary antibody against glutathione have been tested with competition assays in tissue sections using bona fide GSH and GSSG as the target and a range of displacers. No measurable glutardialdehyde-fixed tissue cross-reactivity against L-alanine, $\gamma$-aminobutyrate, 1-amino-4-guanidobutane, D/L-arginine, D/L-aspartate, L-citrulline, L-cysteine, D/L-glutamate, D/L-glutamine, glycine, L-lysine, L-ornithine, L-serine, taurine, L-threonine, L-tryptophan, Ltyrosine was detected. Additionally, the antibody did not bind to glutathionylated proteins on Western blot experiments nor to glutathionylated proteins in sections fixed with formaldehyde (see technical note for glutathione antibody on the website of the manufacturer www. immunologics.com). Therefore, a reaction of the antibody with glutathionylated proteins bound by glutardialdehyde to the protein matrix of the tissue on ultrathin section seems very unlikely (Zechmann et al. 2008). The antibody does not discriminate between free reduced and oxidized glutathione (according to Signature Immunologics Inc.). The primary antibody against cysteine was tested against a spectrum of antigens to assure hapten selectivity and proper affinity. No measurable glutardialdehyde-fixed tissue cross-reactivity was found against methionine, glutathione, cysteic acid, and serine (according to Millipore Corp., Billerica, MA, USA). Several negative controls were made to confirm the specificity of the immunogold procedure. Negative controls were treated either with: (1) gold-conjugated secondary antibody (goat antirabbit $\mathrm{IgG}$ ) without prior incubation of the section with the primary antibody, (2) nonspecific secondary antibody (goat antimouse $\mathrm{IgG}$ ), (3) preimmune serum instead of the primary antibody, and (4) primary antibodies preadsorbed with an excess of glutathione or cysteine for $2 \mathrm{~h}$ at RT prior to labeling of the sections. For the latter, a solution containing $10 \mathrm{mM}$ of glutathione or cysteine was incubated with $0.5 \%$ glutardialdehyde for $1 \mathrm{~h}$. The excess of glutardialdehyde was then saturated by incubation for $30 \mathrm{~min}$ in a solution of $1 \%$ $(w / v)$ BSA. The resulting solutions were used to saturate the glutathione antibody or the cysteine antibody for $2 \mathrm{~h}$ prior to its use in the immunogold labeling procedure described above. 
Quantitative determination of glutathione levels using enzymatic method

For enzymatic method of glutathione determination, cyanobacterial cells were grown in BG-11 medium for 7 days as described above. For sulfur depletion, cells were harvested by 5 -min centrifugation at $2,500 \times g$ and resuspended in BG-11 without sulfur. This step was repeated for five times to ensure complete washing of sulfur-containing medium. Following that, cell cultivation was extended for additional $48 \mathrm{~h}$ in above-mentioned conditions. Cells were pelleted by 5 -min centrifugation at $2,500 \times \mathrm{g}$ and washed with PBS (pH 7,4, containing $137 \mathrm{mM} \mathrm{NaCl}, 2,7 \mathrm{mM} \mathrm{KCl}$, $\left.8 \mathrm{mM} \mathrm{Na}_{2} \mathrm{HPO}_{4}, 1,5 \mathrm{mM} \mathrm{KH} \mathrm{PO}_{4}\right)$. This step was repeated three times. Then, cells were lysed for $30 \mathrm{~min}$ in lysis buffer (10 mM NaHPO $4,5 \mathrm{mM}$ EDTA) and sonicated for 4 min (in 1-min intervals) at $40 \mathrm{~W}$ on ice. Cell debris was removed by $10,000 \times g$ centrifugation step, at $+4^{\circ} \mathrm{C}$ for 15 min. Using clear supernatant, the amount of GSH was measured enzymatically, based on the reduction of 5,5'dithiobis-(2-nitrobenzoic acid) by the glutathione reductase system (Tietze 1969).

\section{Quantitative analysis of immunogold labeling}

Micrographs of randomly photographed immunogoldlabeled sections of cyanobacteria were digitized, and gold particles were counted automatically using the software
Fig. 2 Transmission electron micrographs showing the ultrastructure $(\mathbf{a}, \mathbf{b})$ and the distribution of gold particles bound to glutathione (c, e) and cysteine $(\mathbf{d}, \mathbf{f})$ within Synechocystis sp. cells grown in media with $(+\mathrm{S})$ and without $(-S)$ the addition of sulfur. Gold particles bound to glutathione and cysteine can be found in interthylakoidal spaces (arrows) but not in intrathylakoidal spaces. Note that cells cultivated on media without sulfur contained less gold particles bound to glutathione and cysteine than cells grown on media with sulfur. Bars $=$ $0.5 \mu \mathrm{m}$. $C$ carboxysomes, $C G$ cyanophycin globules, $V$ small vacuoles

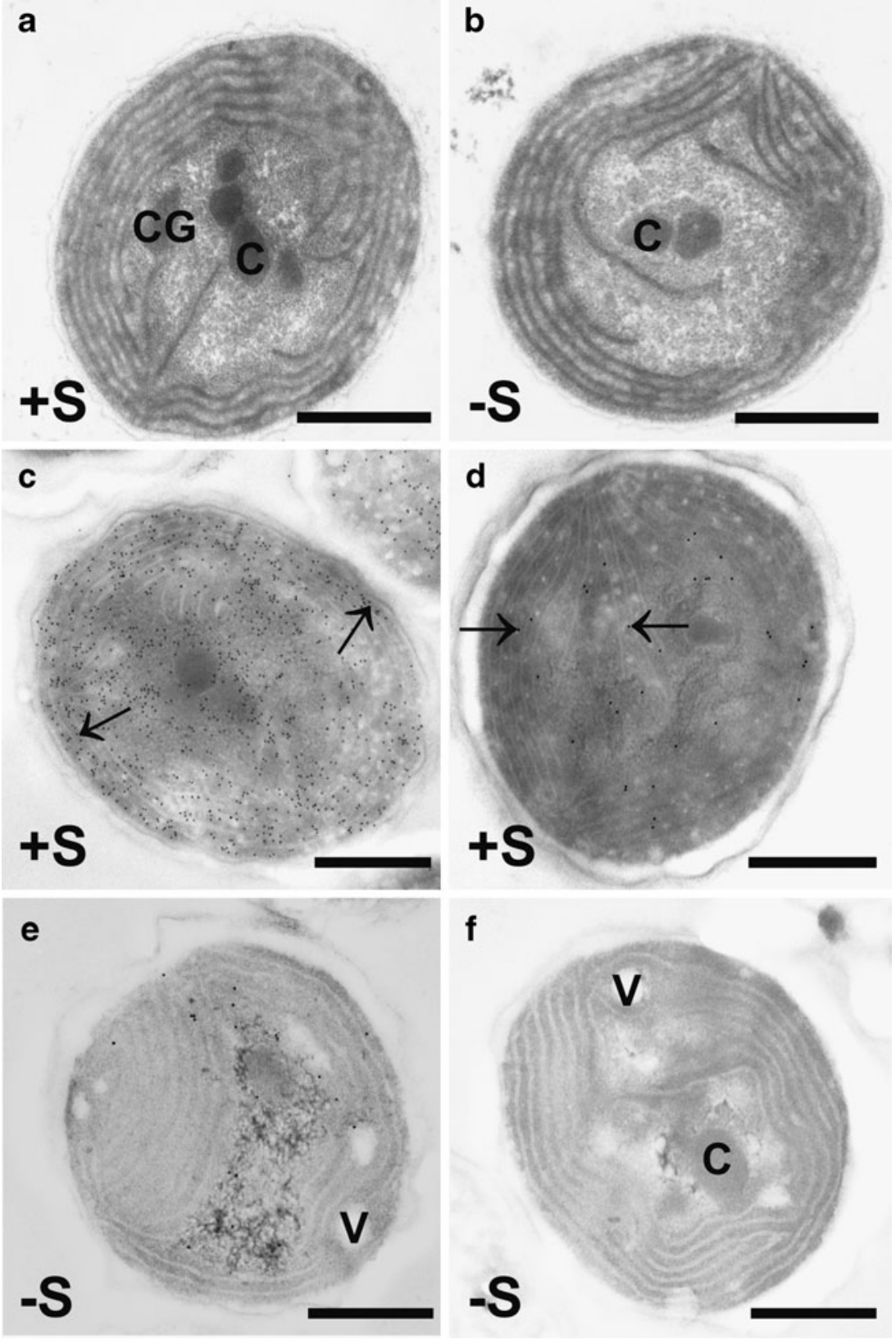


Table 1 Ratio of glutathione between cell compartments

Ratio of glutathione in percent

\begin{tabular}{lcccc}
\cline { 2 - 4 } & \multicolumn{2}{c}{ Glutathione } & & \multicolumn{2}{c}{ Cysteine } \\
\cline { 2 - 5 } & Cytosol & Membranes & Cytosol & Membranes \\
\hline Synechocystis sp. $+\mathrm{S}$ & $49^{\mathrm{a}}$ & $51^{\mathrm{a}}$ & $58^{\mathrm{a}}$ & $42^{\mathrm{b}}$ \\
Synechocystis sp. $-\mathrm{S}$ & $48^{\mathrm{a}}$ & $52^{\mathrm{a}}$ & nd & nd \\
\hline
\end{tabular}

Ratio (in percent) of the distribution of gold particles bound to glutathione between cell compartments where glutathione and cysteine could be detected. $P<0.05$ was regarded significant, analyzed by the Kruskal-Wallis test, followed by post hoc comparison according to Conover. $n>50$ $n d$ not detected

package Optimas 6.5.1 (Media Cybernetics Inc., Bethesda, $\mathrm{MD}$, USA) and Cell $\mathrm{D}$ with the particle analysis tool (Olympus, Life and Material Science Europa GmbH, Hamburg, Germany). For statistical evaluation, 20 to 60 sectioned cells from three different embeddings were analyzed for gold particle density. The obtained data were statistically evaluated using Statistica (Stat-Soft, USA, 2002) and presented as the number of gold particles per square micrometer. For statistical analyses, either the nonparametric Kruskal-Wallis test followed by a post hoc comparison according to Conover or the Mann-Whitney U test were used (Bortz et al. 2000).

\section{Results}

Ultrastructural investigations revealed no difference between intact cells grown on media with and without sulfur, $48 \mathrm{~h}$ after sulfur starvation, even though cell growth in bacteria cultivated in media without sulfur started to stagnate at this time (Fig. 1). Nevertheless, all cells showed a dense cytosol-containing thylakoidal membranes mainly organized in the form of concentric layers proximal to the plasma membrane. Membranes were well preserved and interthylakoidal and intrathylakoidal spaces could be distinguished clearly (Fig. 2a, b). Single thylakoid membranes could also be occasionally observed in the interior (Fig. 2a, b) of the cells. The cytosol contained carboxysomes which contain the enzyme RuBP-carboxylase in tightly packed crystalline arrays and cyanophycin granules (Fig. 2a, b). Additionally, small vacuoles could be occasionally observed within Synechocystis sp. Cells were surrounded by a well-preserved cell wall.

Immunohistochemical detection of glutathione and cysteine revealed that both substances occurred throughout the cytosol of Synechocystis sp. Gold particles were not found inside carboxysomes, cyanophycin granules, cell walls, intrathylakoidal spaces, periplasm, and vacuoles (Fig. 2c, d). Nevertheless, gold particles bound to glutathione and cysteine could be found in interthylakoidal spaces through- out the cells (Fig. 2c, d). Glutathione was distributed evenly within cyanobacteria. No differences in the ratio of glutathione could be observed between the areas that contained membranes and the inner part of the cyanobacteria that did not contain membranes (Table 1). A higher ratio of gold particles bound to cysteine (16\%) was found in areas that did not contain membranes than in those parts of the cyanobacteria that did contain membranes (Table 2).

The accuracy of the obtained immunogold labeling was supported by several observations. In Synechocystis sp. cells grown on media without sulfur, gold particles bound to glutathione and cysteine were strongly decreased by $98.5 \%$ and $100 \%$, respectively, when compared to the control (Fig. 2e, f and Table 2). In addition, analysis of Synechocystis sp. with altered glutathione levels revealed a strong correlation between biochemically determined total glutathione levels. Cells grown on media without sulfur contained about $91 \%$ less glutathione than cells grown on media with sulfur (Fig. 3). No labeling was observed after sections were treated with (1) gold-conjugated secondary antibody without prior incubation with the primary antibody, (2) nonspecific secondary antibody, (3) with preimmune serum instead of the primary antibody and (4) primary antibodies against glutathione and cysteine which were preadsorbed with an excess of glutathione and cysteine (Fig. 4a, b).

Table 2 Data are means \pm standard errors and document the amount of gold particles bound to glutathione and cysteine per micrometer in Synechocystis sp. cells grown in media with $(+\mathrm{S})$ and without $(-\mathrm{S})$ the addition of sulfur

\begin{tabular}{lll}
\hline & \multicolumn{2}{c}{ Gold particles per micrometer } \\
\cline { 2 - 3 } & Glutathione & Cysteine \\
\hline Synechocystis sp. $+\mathrm{S}$ & $268 \pm 12.5^{*}$ & $39.38 \pm 3.7^{*}$ \\
Synechocystis sp. $-\mathrm{S}$ & $4.3 \pm 1.1$ & $0 \pm 0$ \\
\hline$n>50$ & & \\
$* P<0.001$ (regarded as significant, analyzed with Mann-Whitney $U$ \\
test)
\end{tabular}




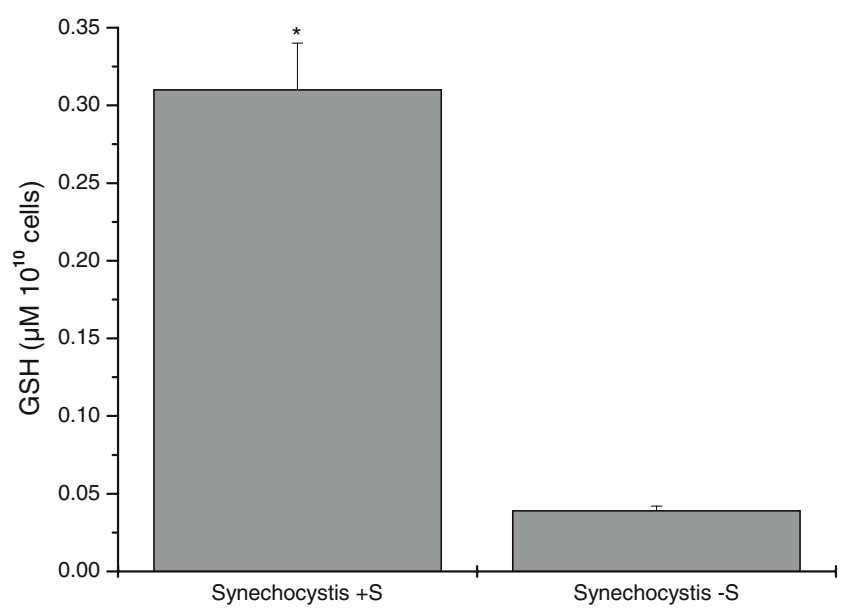

Fig. 3 Graph shows means with standard errors and documents the amount of glutathione in micromolar per cell number in Synechocystis sp. cells grown in media with $(+S)$ and without $(-S)$ the addition of sulfur. $P<0.05(*)$ was regarded significant analyzed with MannWhitney $U$ test

\section{Discussion}

Cells of Synechocystis sp. grown on media with sulfur showed typical ultrastructural features similar to those previously described for cyanobacteria (Lee et al. 2000; Liberton et al. 2006). No obvious ultrastructural differences were found between intact cells grown on media with and without sulfur, indicating that sulfur depletion for $48 \mathrm{~h}$ did not cause major ultrastructural changes in Synechocystis sp. cells, even though a stagnation of growth could be observed after that time when compared to bacteria grown in media with sulfur.

The present study revealed a deeper insight into the subcellular distribution of glutathione and cysteine in Synechocystis sp. The distribution of glutathione and cysteine was found to be mainly restricted to the cytosol and interthylakoidal spaces. Whereas glutathione was evenly distributed in areas that contained membranes and areas that did not contain membranes, slightly more cysteine was detected within the latter one. No glutathione and cysteine was detected in carboxysomes, vacuoles, intrathylakoidal spaces, and the periplasm. These data indicate that glutathione and cysteine do not play an important role in these cell compartments in Synechocystis sp. Glutathione and cysteine were present in interthylakoidal spaces but not in intrathylakoidal spaces. Similar results were found for the subcellular distribution of glutathione in plastids of plant cells (Zechmann et al. 2006a, b, 2008) which are thought to be derived from endosymbiosis of cyanobacteria in a eukaryotic cells (Vesteg et al. 2009; Waters and Langdale 2009). In chloroplasts and plastids of plants, glutathione and cysteine were restricted to the stroma but did not occur in intrathylakoidal spaces (Zechmann et al. 2006a, b, 2008). Considering these data, there is a good correlation of the subcellular distribution of glutathione and cysteine between cyanobacteria and plastids in plant cells. These results indicate that the subcellular distribution of glutathione and cysteine in plastids remained conserved during evolution despite partly new and different subcellular functions and roles in plant cells when compared to cyanobacteria. Nevertheless, glutathione and cysteine syntheses in plants take place in plastids and primarily in the cytosol of plant cells. Additionally, cysteine, $\gamma$-glutamyl-cysteine, and glutathione can be transported across the chloroplast envelope and glutathione can also be imported into other cell compartments that are not able to synthesize glutathione such as mitochondria (Wachter et al. 2005; Zechmann et al. 2008; Foyer and Noctor 2009; Krueger et al. 2009; Maughan et al. 2010). Thus, it becomes evident that even though eukaryotes acquired glutathione metabolism through endosymbiotic events of cyanobacteria (Fahey et al. 1987, Fahey and Sundquist 1991) its metabolism and subcellular distribution in higher plants have been modified most probably due to
Fig. 4 Transmission electron micrographs showing sections of Synechocystis sp. treated as negative controls. Both images show lack of labeling as the primary antibody was saturated with an excess of glutathione (a) and cysteine (b) prior to its application. Bars $=0.5 \mu \mathrm{m}$
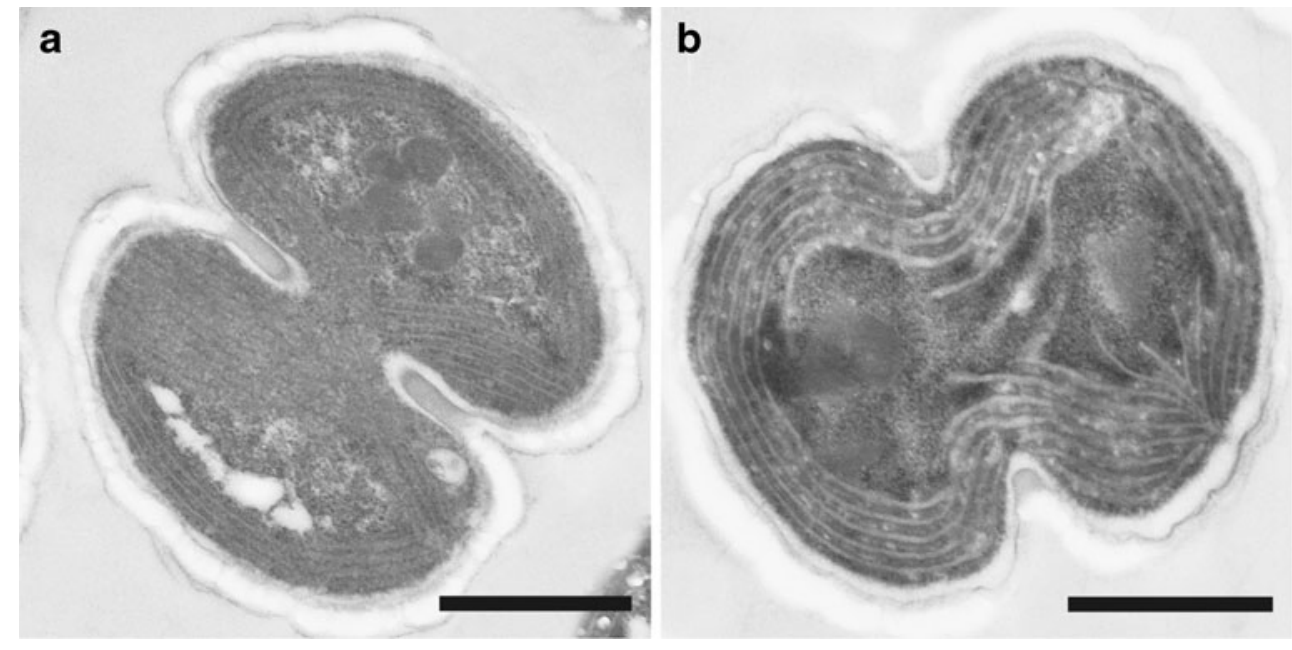
different and more effective defense strategies against environmental stress situations.

It is interesting that glutathione was not detected in the periplasmic spaces and cell walls. It has been shown in $E$. coli that $\gamma$-glutamyl-transpeptidase (responsible for glutathione degradation by cleaving the $\gamma$-peptide bond between glutamate and cysteine) is a periplasmic protein (Suzuki et al. 1986) whereas in Neisseria meningitides it is associated with the inner membrane facing the cytoplasm (Takahashi and Watanabe 2004). The same has also been found for plant cells (Ohkama-Ohtsu et al. 2007). Additionally, it was postulated that bacteria excrete large amounts of glutathione into the extracellular space (Owens and Hartman 1986). The lack of glutathione labeling in the periplasm and cell walls in this study suggests that either glutathione degradation does not occur in the periplasm and cell walls of cyanobacteria or that it takes place very rapidly in these cell compartment so that free glutathione occurs in such low concentrations that it cannot be detected with this method. Additionally, these results indicate that the excretion of large amounts of glutathione through the periplasm in cyanobacteria is unlikely at least under physiological environmental conditions.

The accuracy of the observed labeling is supported by the results of the preadsorption experiments of the antibodies against glutathione and cysteine with glutathione and cysteine, respectively, and by the fact that a signal was not obtained after the preadsorption of the sections with preimmune serum. Additionally, sulfur starvation led to a complete loss of cysteine labeling and to a $98.5 \%$ decrease of glutathione labeling when compared to Synechocystis sp. cells grown on media with sulfur. These data also correlate well with results obtained from biochemical investigations which showed that cells grown on media without sulfur contained about 91\% less glutathione when compared to cells grown on media with sulfur. From these investigations, it becomes obvious that in situations of sulfur starvation the rate of glutathione and cysteine degradation must exceed glutathione and cysteine synthesis due to the reduced ability of the cell to perform sulfur assimilation into cysteine.

Summing up the present study revealed a deeper insight into the subcellular distribution of glutathione and cysteine in cyanobacteria. Both components are restricted to the cytosol of Synechocystis sp. and do not occur in intrathylakoidal spaces, carboxysomes, cyanophycin granules, vacuoles, and the periplasm. Experiments under sulfur depletion revealed that both glutathione and cysteine were strongly decreased $48 \mathrm{~h}$ after the beginning of the sulfur starvation. This method can now be used to investigate the importance of subcellular glutathione and cysteine metabolism in cyanobacteria during different environmental (stress) situations such as oxidative and osmotic stress, acidic conditions, and exposure to toxic components.

Acknowledgement This work was supported by the Austrian Science Fund (FWF, P20619 to B.Z.), Austrian-Croatian exchange grants (WTZ HR 30-2008 and MSES 533-06-07-0002), and the Croatian Ministry of Science, Education, and Sports research grant (098-0982913-2838 to H. F.). We would like to thank Nikolina Stojanović and Maja Osmak for their kind help with the determination of glutathione levels. The authors declare that they have no conflict of interest.

Open Access This article is distributed under the terms of the Creative Commons Attribution Noncommercial License which permits any noncommercial use, distribution, and reproduction in any medium, provided the original author(s) and source are credited.

\section{References}

Bortz J, Lienert GA, Bohenke K (2000) Verteilungsfreie methoden in der biostatistik. Springer, Berlin

Carmel-Harel O, Storz G (2000) Roles of the glutathione- and thioredoxin-dependent reduction systems in the Escherichia coli and Saccharomyces cerevisiae responses to oxidative stress. Annu Rev Microbiol 54:439-461

Chesney JA, Eaton JW, Mahoney JR Jr (1996) Bacterial glutathione: a sacrificial defense against chlorine compounds. J Bacteriol $178: 2131-2135$

Csonka LN (1989) Physiological and genetic responses of bacteria to osmotic stress. Microbiol Rev 53:121-147

Copley SD, Dhillon JK (2002) Lateral gene transfer and parallel evolution in the history of glutathione biosynthesis genes. Gen Biol 3:0025.1-0025.16

Fahey RC (2001) Novel thiols of prokaryotes. Annu Rev Microbiol $55: 333-356$

Fahey RC, Sundquist AR (1991) Evolution of glutathione metabolism. Adv Enzymol Relat Areas Mol Biol 64:1-53

Fahey RC, Buschbacher RM, Newton GL (1987) The evolution of glutathione metabolism in phototrophic microorganisms. J Mol Evol 25:81-88

Ferguson GP, Booth IR (1998) Importance of glutathione for growth and survival of Escherichia coli cells: detoxification of methylglyoxal and maintenance of intracellular $\mathrm{K}+$. J Bacteriol 180:4314-4318

Forman HJ, Zhang H, Rinna A (2009) Glutathione: overview of its protective roles, measurement, and biosynthesis. Mol Aspects Med 30:1-12

Foyer CH, Noctor G (2009) Redox regulation and photosynthetic organisms: signaling, acclimation, and practical implications. Antioxid Redox Signal 11:861-905

Hjelle OP, Chaudhry FA, Ottersen OP (1994) Antisera to glutathione: characterization and immunocytochemical application to the rat cerebellum. Eur J NeuroSci 6:791-804

Hurd TR, Costa NJ, Dahm CC, Beer SM, Brown SE, Filipovska A, Murphy MP (2005) Glutathionylation of mitochondrial proteins. Antioxid Redox Signal 7:999-1010

Huster D, Hjelle OP, Haug FM, Nagelhus EA, Reichelt W, Ottersen OP (1998) Subcellular compartmentation of glutathione and glutathione precursors. A high resolution immunogold analysis of the outer retina of guinea pig. Anat Embryol 198:277-287

Krueger S, Niehl A, Lopez Martin MC, Steinhauser D, Donath A, Hildebrandt T, Romero LC, Hoefgen R, Gotor C, Hesse H (2009) 
Analysis of cytosolic and pastidic serine acetyltransferase mutants and subcellular metabolite distributions suggests interplay of the cellular compartments for cysteine biosynthesis in Arabidopsis. Plant Cell Environ 32:349-367

Lafiti A, Ruiz M, Zhang CC (2009) Oxidative stress in cyanobacteria. FEMS Microbiol Rev 33:258-278

Lee S, Owen HA, Prochaska DJ, Barnum SR (2000) HSP16.6 is involved in the development of thermotolerance and thylakoid stability in the unicellular cyanobacterium, Synechocystis sp. PCC 6803. Curr Microbiol 40:283-287

Liberton M, Berg RH, Heuser J, Roth R, Pakrasi HB (2006) Ultrastructure of the membrane systems in the unicellular cyanobacterium Synechocystis sp. strain PCC 6803. Protoplasma 227:129-138

Masip L, Veeravalli K, Georgiou G (2006) The many faces of glutathione in bacteria. Antioxid Redox Signal 8:753-761

Maughan SC, Pasternak M, Cairns N, Kiddle G, Brach T, Jarvis R, Haas F, Nieuwald J, Lim B, Müller C, Salcedo-Sora E, Kruse C, Orsel M, Hell R, Miller AJ, Bray P, Foyer CH, Murray JAH, Meyer A, Cobbett CS (2010) Plant homologs of the plasmodium falciparum chloroquine-resistance transporter. PfCRT, are required for glutathione homeostasis and stress responses. PNAS. doi:10.1073/pnas.0913689107

McLaggan D, Logan TM, Lynn DG, Epstein W (1990) Involvement of gamma-glutamyl peptides in osmoadaptation of Escherichia coli. J Bacteriol 172:3631-3636

Newton GL, Arnold K, Price MS, Sherrill C, del Cardayr'e SB, Aharonowitz Y, Cohen G, Davies J, Fahey RC, Davis C (1996) Distribution of thiols in microorganisms: mycothiol is a major thiol in most actinomycetes. J Bacteriol 178:1990-1995

Ohkama-Ohtsu N, Radwan S, Peterson A, Zhao P, Badr AF, Xiang C, Oliver DJ (2007) Characterization of the extracellular c-glutamyl transpeptidases, GGT1 and GGT2, in Arabidopsis. Plant J 49:865-877

Owens RA, Hartman PE (1986) Export of glutathione by some widely used Salmonella typhimurium and Escherichia coli strains. J Bacteriol 168:109-114

Rennenberg H (2001) Glutathione-an ancient metabolite with modern tasks. In: Grill D, Tausz M, De Kok LJ (eds) Significance of glutathione to plant adaptation to the environment. Kluwer, Dordrecht, pp 1-11

Riccillo PM, Muglia CI, de Bruijn FJ, Roe AJ, Booth IR, Aguilar OM (2000) Glutathione is involved in environmental stress responses in Rhizobium tropici, including acid tolerance. $\mathrm{J}$ Bacteriol 182:1748-1753
Smirnova GV, Krasnykh TA, Oktyabrsky ON (2001) Role of glutathione in the response of Escherichia coli to osmotic stress. Biochem (Mosc) 66:973-978

Sørensen S (1909) Über die messung und die bedeutung der wasserstoffionenkonzentration bei enzymatischen prozessen (mit einer ergänzung). Biochem Z 21:131-304

Storz G, Imlay JA (1999) Oxidative stress. Curr Opin Microbiol 2:188-194

Suzuki H, Kumagai H, Tochikura T (1986) Gamma-glutamyl transpeptidase from Escherichia coli K-12: formation and localization. J Bacteriol 168:1332-1335

Takahashi H, Watanabe H (2004) Post-translational processing of Neisseria meningitidis gamma-glutamyl aminopeptidase and its association with inner membrane facing to the cytoplasmic space. FEMS Microbiol Lett 234:27-35

Tausz M (2001) The role of glutathione in plant response and adaptation to natural stress. In: Grill D, Tausz M, De Kok LJ (eds) Significance of glutathione in plant adaptation to the environment. Kluwer Academic Publishers, Netherlands, pp 101-122

Tietze F (1969) Enzymic method for quantitative determination of nanogram amounts of total and oxidized glutathione: applications to mammalian blood and other tissues. Anal Biochem 27:502-522

Van Breusegem F, Dat JF (2006) Reactive oxygen species in plant cell death. Plant Physiol 141:384-390

Vesteg M, Vacula R, Krajcovic J (2009) On the origin of chloroplasts, import mechanisms of chloroplast-targeted proteins, and loss of photosynthetic ability-review. Fol Microbiol 54:303-321

Wachter A, Wolf S, Steininger H, Bogs J, Rausch T (2005) Differential targeting of GSH1 and GSH2 is achieved by multiple transcription initiation: implications for the compartmentation of glutathione biosynthesis in the Brassicaceae. Plant J 41:15-30

Waters MT, Langdale JA (2009) The making of chloroplast. EMBO J 28:2861-2873

Zechmann B, Müller M, Zellnig G (2006a) Intracellular adaptations of glutathione content in Cucurbita pepo (L.) induced by reduced glutathione and buthionine sulfoximine treatment. Protoplasma 227:197-209

Zechmann B, Zellnig G, Müller M (2006b) Immunocytochemical localization of glutathione precursors in plant cells. J Electron Microsc 55:173-181

Zechmann B, Mauch F, Sticher L, Müller M (2008) Subcellular immunocytochemical analysis detects the highest concentrations of glutathione in mitochondria and not in plastids. J Exp Bot 59:4017-4027 